\title{
Experimental study of moist air flow in the gap between the aircraft's fuselage and its cabin wall
}

\author{
Andreas Westhoff ${ }^{1} \cdot$ Claus Wagner $^{1,2}$
}

Received: 17 September 2019 / Revised: 9 January 2020 / Accepted: 20 January 2020 / Published online: 5 February 2020

(c) The Author(s) 2020

\begin{abstract}
We carried out an experimental study on the moisture transfer and the heat transport in warm and humid air flows between the cabin lining and the fuselage skin. The measurements were performed in a rectangular gap channel, representing the space between fuselage and cabin wall. Long-term measurements were performed for three configurations: without insulation, with fibreglass blanket and with melamine resin foam blanket. To simulate realistic flight conditions in a laboratory setup, we applied a concept of scaling. This concept is intended to guarantee similitude between the real flight conditions and the laboratory experiment. The results reveal that without insulation, the moisture transfer rate is much higher compared to the configurations with insulation blankets. With insulation, most of the water evaporates during ground conditions and just a small amount is entrapped in the insulation. Without insulation, just a small part of the frozen water evaporates on the ground. When comparing the two insulation blankets, it is found that they both have a similar heat transmittance coefficient. However, the condensation rate of the water and the resulting accumulation of water are significant, higher for the fibreglass blanket.
\end{abstract}

Keywords Convective air flow $\cdot$ Phase transition $\cdot$ Gap flow $\cdot$ Aircraft cabin $\cdot$ Insulation

\begin{tabular}{|c|c|c|c|}
\hline \multicolumn{2}{|c|}{ Abbreviations } & $\dot{Q}_{\mathrm{s}}$ & Sensible heat flux (W) \\
\hline \multicolumn{2}{|c|}{ Greek } & $\dot{V}$ & Volume flow $\left(\mathrm{m}^{3} / \mathrm{s}\right)$ \\
\hline$\alpha$ & Heat transfer coefficient $\left(\mathrm{W} / \mathrm{m}^{2} \mathrm{~K}\right)$ & $\ell$ & Characteristic length (m) \\
\hline$\beta$ & Thermal expansion coefficient $(1 / \mathrm{K})$ & $\mathbf{u}$ & Velocity vector $(\mathrm{m} / \mathrm{s})$ \\
\hline$\delta \rho$ & Vapour density gradient $\left(\mathrm{kg} / \mathrm{m}^{2}\right)$ & A & Surface area $\left(\mathrm{m}^{2}\right)$ \\
\hline$\lambda$ & Thermal conductivity (W/m K) & $A_{\mathrm{D}}$ & Diffusion area $\left(\mathrm{m}^{2}\right)$ \\
\hline$\tau$ & Mean passing time (s) & $c_{\mathrm{p}}$ & Specific heat capacity $(\mathrm{J} / \mathrm{Kg} \mathrm{K})$ \\
\hline$\Theta$ & Dewpoint temperature (K) & $D$ & Diffusion coefficient $\left(\mathrm{m}^{2} / \mathrm{s}\right)$ \\
\hline$\rho$ & Fluid density $\left(\mathrm{kg} / \mathrm{m}^{3}\right)$ & $d$ & Thickness (m) \\
\hline & Vapour density $\left(\mathrm{kg} / \mathrm{m}^{3}\right)$ & $D_{\mathrm{h}}$ & Mean inflow velocity $\left(\mathrm{m}^{2}\right)$ \\
\hline$\varrho_{\mathrm{v}}$ & vapour density (kg/m²) & $g$ & Gravitational acceleration $\left(\mathrm{m} / \mathrm{s}^{2}\right)$ \\
\hline \multicolumn{2}{|l|}{ Latin } & $H$ & Height of the duct (gap) $\left(\mathrm{m}^{2}\right)$ \\
\hline$\Delta \dot{M}_{\mathrm{v}}$ & Vapour mass transfer due to phase transition $(\mathrm{kg} / \mathrm{s})$ & $H_{\mathrm{y}}$ & Enthalpy of evaporation $(\mathrm{J} / \mathrm{kg})$ \\
\hline$\Delta T$ & Characteristic temperature difference $(\mathrm{K})$ & $k$ & Heat transmission coefficient $\left(\mathrm{W} / \mathrm{m}^{2} \mathrm{~K}\right)$ \\
\hline$\dot{M}$ & Mass flow $(\mathrm{kg} / \mathrm{s})$ & $L$ & Length of the cooling plate $(\mathrm{m})$ \\
\hline \multirow[t]{2}{*}{$\dot{Q}_{1}$} & Latent heat flux due to phase transition (W) & $p$ & Pressure $(\mathrm{Pa})$ \\
\hline & & $T$ & Temperature (K) \\
\hline & 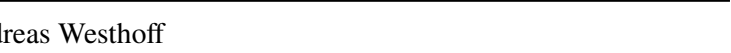 & $t$ & Time (s) \\
\hline & eas.westhoff@dlr.de & $U$ & Characteristic velocity $(\mathrm{m} / \mathrm{s})$ \\
\hline & as Wagner & $U_{\text {in }}$ & Mean inflow velocity $(\mathrm{m} / \mathrm{s})$ \\
\hline & s.wagner@tu-ilmenau.de & $W$ & Width of the cooling plate (m) \\
\hline \multirow{2}{*}{ ctons } & \multirow{2}{*}{$\begin{array}{l}\text { German Aerospace Center, Bunsenstr. 10, } 37073 \text { Göttingen, } \\
\text { Germany }\end{array}$} & \multicolumn{2}{|c|}{ Subscripts } \\
\hline & & air & Airflow \\
\hline \multirow[t]{2}{*}{2} & hnische Universität Ilmenau, Helmholtzring 1, & $\mathrm{b}$ & Bulk \\
\hline & 84 Ilmenau, Germany & CHS & Capacitive humidity sensors \\
\hline
\end{tabular}


d Droplet surface

DPM Dew point mirror

f Fuselage

i Insulation

in Inlet section

1 Laboratory conditions

out Outlet section

$\mathrm{r} \quad$ Real flight scenario

sat Saturation

$\mathrm{t} \quad$ Test section

w Water

\section{Introduction}

The ventilation of a commercial aircraft cabin faces the challenge of maintaining a healthy and comfortable environment and meeting the requirement of being as energy-efficient as possible. With the aim to provide both well-being of the passengers and energy efficiency, several concepts of aircraft cabin ventilation were introduced in the last decades. A plethora of experimental and numerical studies have been performed to characterise the velocity and temperature distribution in aircraft cabins [1-3]. Further studies investigated novel and alternative ventilation concepts under the aspect of ventilation efficiency or thermal comfort $[1,4,5]$.

Nowadays, mixing ventilation $[6,7]$ is the common practice in passenger aircraft. Mixing ventilation is characterised by cold air which enters the cabin near the luggage compartments at the ceiling and warm air being drawn off near the cabin floor. The interaction of the faster moving incoming air with the slower natural convection, induced by the passengers, leads to a mixing of the hot and cold air flow. During the flight, the moisture emitted by the passenger mixes with the cabin air. The largest amount of the moist air leaves the cabin through the outlets near the cabin floor. A smaller amount of air enters the gap between fuselage and cabin wall due to leakage. Considering that at a typical altitude of $11,000 \mathrm{~m}$, the ambient temperature can be as low as $-65^{\circ} \mathrm{C}$ [8], the temperature in the gap falls below the dew point and the vapour in the moist air condensates. Consequently, if the temperature is below the freezing point, the condensation water freezes. Since the state-of-the-art insulation blankets are made of fibreglass, which acts as a porous medium, the condensation water accumulates in the fibre glass blankets. For a commercial passenger plane on a long-haul flight, it has been reported that up to $680 \mathrm{~kg}[9,10]$ of water accumulates in the insulation packages due to leakages between the gap and the cabin. As a result, the soaked blankets reinforce shell corrosion, reduce the thermal insulation, worsen the noise reduction performance and increase fuel consumption. All these effects either generate additional costs or negatively impact the well being of the passengers.
Considering alternative ventilation concepts like displacement ventilation [11-13] in combination with its socalled active gap flow, where the moist cabin air returns through the gap between fuselage and cabin wall, the effect of condensation and thus the accumulation of water in the insulation packages can be even higher. Characteristic for displacement ventilation is that the cold air enters the cabin close to the floor, is heated up by the passengers where it rises due to buoyancy. In the following, the rising air heats up even further and mixes with the moist air emitted by the passengers and leaves the cabin in the area above the luggage compartments. From there on, the air cools down again and descends in the gap between fuselage and cabin wall.

Taking into account that the entire warm and moist cabin air passes the gap between fuselage and the cabin wall, the consequences for the heat transport and mass transfer due to phase transition are not unknown. With regard to the active gap flow for displacement ventilation, it is known that the temperatures in the gap are higher than for mixing ventilation without gap flow. Furthermore, the air humidity, respectively, the vapour mass flow, is larger. These two competing effects can result in a higher or lower condensation rate. Studying the state-of-the-art mixing ventilation, Zhang et al. [14] report that an additional stream of warm air in an air channel between the primary insulation and the cabin wall effectively increases the insulation of an aircraft. However, in the case of the active gap flow, the increased mass flow of vapour might result in higher condensation rates, and thus more condensation water accumulates in the insulation blankets. The consequence is a weaker thermal insulation effect. Moreover, due to the very low ambient temperatures during the cruise flight, the condensation water freezes and the growing ice layer might lead to an obstruction of the air channel. On the contrary, the additional warm air stream improves the insulation and thus reduces the condensation rate. It must be noted that the air stream barrier in the gap could even make an insulation redundant.

The above-mentioned overview reveals the uncertainties of an active gap flow regarding thermal insulation efficiency and safety aspects as well as the potential to improve the aircraft insulation. However, the interaction of convective air flow, mass diffusion and latent heat due to phase transition makes a valid prediction of the impact on the insulation impossible. With the objective to determine whether it is possible to realise concepts like displacement ventilation in combination with active gap flow in a commercial passenger aircraft, we performed an experimental study on the heat transport and mass transfer in a generic gap representing the area between the fuselage and the cabin wall for three different configurations: without an insulation blanket, with an insulation blanket made of fibreglass (common) and one made of melamine resin foam. Moreover, to simulate realistic flight conditions in a laboratory setup, we introduced 
a concept of scaling. This concept provides similitude of the heat transport and mass transfer for laboratory and real flight conditions.

\section{Model equations, similitude and scaling}

The physical processes of the resulting heat transport and mass transfer of the moist air flow in the gap are determined by the mutual interplay of forced convection, phase transition and vapour mass diffusion. With the objective to identify the system-relevant parameters and mechanisms, a survey of the processes of convective air flow with phase transition and diffusion for the present configuration is introduced. Based on this analysis, a concept of scaling allowing to perform flight measurements in a laboratory by simulating a real flight under the conditions of similitude is developed.

\subsection{Convective air flow with phase transition}

Figure 1 illustrates the physical processes in a simplified configuration representing the gap between the fuselage and the cabin wall of an aircraft for the climb, cruise, descent and ground period. The following characterisation focuses on the processes of condensation, freezing and deposition. However, it is similar for evaporation, melting and sublimation. The differences in comparison with the processes of condensation, freezing and deposition will be discussed at the end of this section.

On the left-hand side is a vertically oriented cooled boundary representing the fuselage of an aircraft. Above this boundary is the layer of phase transition in which the fluid temperature is below the dew point (coloured light blue) and droplets of the condensation water occur. In addition, the dashed grey line represents the boundary where the fluid temperature equals the saturation temperature. The orange-coloured layer represents the insulation blanket. On the right-hand side of the insulation blanket is the gap of the moist air flow. In the experimental setup, moist air with a constant dew point temperature $\Theta_{\text {in }}$ enters the gap at the top and moves downwards. Additionally, the velocity profile $\partial u / \partial x$ is highlighted in grey. Taking into account that the fluid temperature is always higher than the temperature of the wall on the left side, this leads to the conclusion that the moist air is cooling down. If the fluid temperature falls below the dew point, water condensates and if the temperatures is below the freezing point, the water freezes and an ice layer is formed. As a consequence, latent heat is released due to phase transition. The corresponding heat flux due to phase change is

$\dot{Q}_{1}=\Delta \dot{M}_{\mathrm{v}} H_{\mathrm{v}}$,

where $\Delta \dot{M}_{\mathrm{v}}$ denotes the mass transfer due to phase transition and $H_{\mathrm{v}}$ the enthalpy of evaporation. The primary mass transfer takes place directly on the cooled wall and a smaller part of vapour already condensates in the fluid. As a result of the phase transition in the air, large density gradients develop locally, resulting in localised convective flow in the boundary layer above the cooled wall. Furthermore, the temperature difference between the cooled wall $T_{\mathrm{b}}$ and the air flow $T_{\infty}$ leads to an additional convective heat transport $\dot{Q}_{\mathrm{c}}$. In the present case, we assume that the buoyancy forces are much smaller than the inertia forces. Hence, the heat transport is determined by forced convective flow. If the gap is additionally equipped with an insulation blanket, the sensible heat flux between the gap flow and the fuselage

$\dot{Q}_{\mathrm{s}}=k A_{\mathrm{f}} \Delta T$,

depends on the temperature difference $\Delta T=T_{\mathrm{b}}-T_{\mathrm{f}}$ between the mixing temperature and fuselage temperature, the area of the fuselage surface $A_{\mathrm{f}}$ and the heat transmission coefficient

$$
k=\left(\sum_{j}\left(\frac{1}{\alpha_{\mathrm{i}}^{\mathrm{j}}}\right)+\frac{d_{\mathrm{i}}}{\lambda_{\mathrm{i}}}+\frac{d_{\mathrm{f}}}{\lambda_{\mathrm{f}}}\right)^{-1} .
$$

Fig. 1 Illustration of heat transport, mass transfer due to phase transition and vapour diffusion in a gap wind tunnel with insulation blanket in case of condensation: temperature gradient (red), velocity profile (grey) and diffusion gradient (blue). The insulation material is coloured yellow, and the area where the fluid temperature is below the dew point is coloured light blue

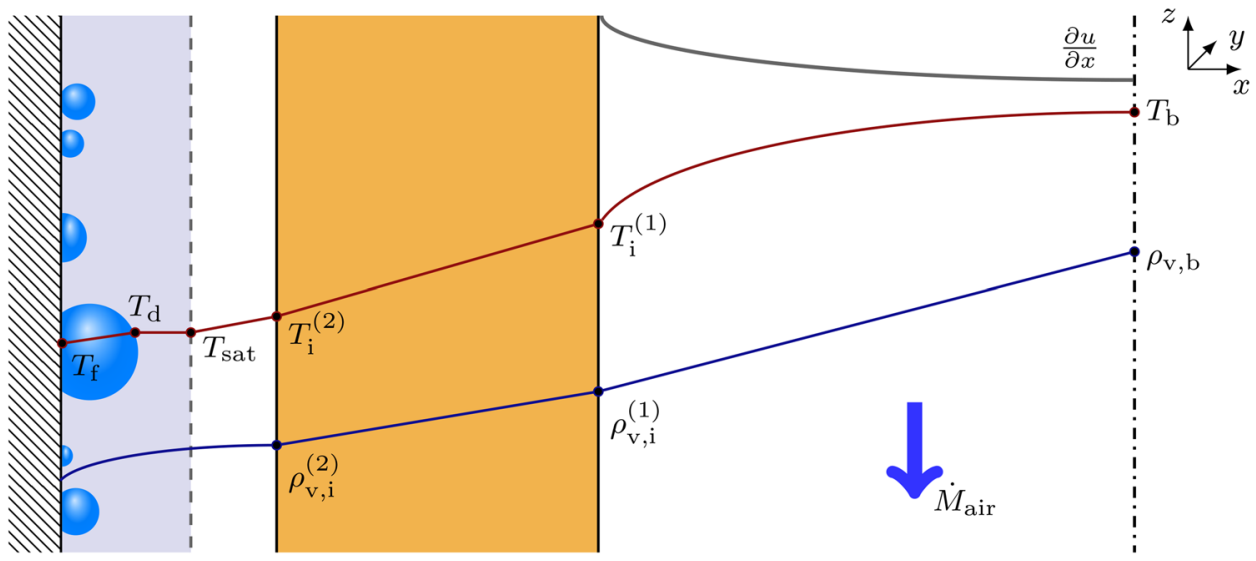


The transmission coefficient is determined using the heat transfer coefficients of the interfaces $\alpha_{i}^{j}$, the thickness of the water or ice layer (droplets) at the cooled boundary $d_{\mathrm{f}}$ and the insulation material $d_{\mathrm{i}}$ as well as the corresponding thermal conductivity $\lambda_{\mathrm{f}}$ and $\lambda_{\mathrm{i}}$, respectively. As a result, a temperature profile between the moist air flow and the fuselage develops (Fig. 1, red). Furthermore, $T_{\mathrm{i}}$ denotes the temperature at the interface of the insulating material, $T_{\text {sat }}$ the saturation temperature, $T_{\mathrm{w}}$ the temperature at the surface of the water or ice agglomerations and $T_{\mathrm{f}}$ the temperature of the fuselage. In addition, a vapour pressure gradient and thus, a density gradient of $\partial \varrho_{\mathrm{v}} / \partial x$ develops due to the phase transition on the fuselage. The result is a diffusive mass transfer of vapour

$\dot{M}_{\mathrm{v}}=-D A_{\mathrm{D}} \nabla \varrho_{\mathrm{v}} \mathbf{n}$,

where $D$ denotes the diffusion coefficient of vapour, $A_{\mathrm{D}}$ the diffusion area, $\mathbf{n}$ the surface normal vector, and $\varrho_{\mathrm{v}}$ the vapour density. Moreover, we assume that the mean vapour density in the gap is almost constant for a time period longer than the other relevant time scales of the system and the phase transition primarily takes place in the layer between the fuselage and the primary insulation. In this case, the vapour density between the primary insulation and fuselage is always less or equal to the vapour density in the bulk. The resulting density gradient leads to a vapour mass flow from the bulk through the insulation blankets, where a part of the vapour condensates and remains. Hence, the insulation blanket determines the heat transport as well as the diffusive vapour flow in the present configuration.

The characterisation of the physical processes described above is discussed exemplarily for the heat and mass transfer during the cruise and climb period regarding condensation, freezing and deposition. However, in particular, in case of the descent and the ground period, if the temperature in the gap is above the freezing point or the temperature exceeds the dew point, the ice melts or sublimates and water evaporates. In case of sublimation and evaporation, the process of heat transport and mass transfer is similar. But in contrast to condensation, freezing or deposition, heat is consumed. As a consequence, the direction of the heat transfer and the diffusive mass transfer is reversed. Significant differences can just be found in case of melting. Here, the melting water drains on the vertically oriented fuselage. Therefore, an enhanced heat transfer on the wall is observed [15] caused by the additional fluid flow on the fuselage surface. The difference of the local heat transfer coefficient can amount to $15 \%$. The difference of the global heat transfer for the present configuration is certainly less than $1 \%$ and hence the effect is negligible for the global heat balance.

In the following, we consider the working fluid as a one-phase gas mixture with the exception of the terms representing the latent heat. Hence, the vapour proportion of the moist air is just taken into account in the energy equation regarding the latent heat release or consumption. In addition, the air is assumed as incompressible. Based on this assumption, the system is characterised by the continuity equation, equation of motion and energy equation [16]:

$\frac{\mathrm{D} \varrho}{\mathrm{D} t}=-\varrho \nabla \mathbf{u}$,

$\rho \frac{D \mathbf{u}}{D t}=-\nabla p+\eta \nabla^{2} \mathbf{u}+\mathbf{F}_{\mathrm{b}}$

$\rho c_{p} \frac{\mathrm{D} T}{\mathrm{D} t}=\lambda \nabla^{2} T+\beta T \frac{\mathrm{D} p}{\mathrm{D} t}+D H_{\mathrm{v}} \nabla^{2} \varrho_{\mathrm{v}}$.

In Eqs. (5)-(7) and in the following, the subscript $v$ denotes the fluid properties of the vapour and none of the indices relates to the moist air properties. The fluid properties are the density $\varrho$, the kinematic viscosity $v$, the specific heat capacity $c_{\mathrm{p}}$, the thermal conductivity $\lambda$, the heat expansion coefficient $\beta$, the enthalpy of evaporation $H_{\mathrm{v}}$ and the diffusion coefficient $D$. Further, $t$ is the time, $\mathbf{u}$ the velocity vector, $p$ the pressure, and $T$ the temperature. In addition, the equation of motion (Eq. 6) includes the term for the buoyancy force per volume unit $\mathbf{F}_{\mathrm{b}}=\Delta \rho g \mathbf{e}_{\mathrm{z}}$ due to temperatureinduced density gradients.

Assuming that the spatial gradient of the vapour density corresponds to the vapour mass diffusion and that the incoming vapour density is constant, the term of the latent heat in Eq. (7) can be substituted by $\mathrm{D} \varrho_{\mathrm{v}} / \mathrm{D} t=D \nabla^{2} \varrho_{\mathrm{v}}$. Furthermore, steady-state conditions can be considered for the cruise and ground period as well as for the climb and descent period. In case of the climb and descent, the change of the density is $\partial \rho / \partial t \approx 2 \times 10^{-4} \mathrm{~kg} / \mathrm{m}^{3} \mathrm{~s}$. In addition, for the present configuration and parameter range, the criteria for the application of the Boussinesq approximation [17] $g \rho \beta \ll 1, g \alpha L / c_{\mathrm{p}} \ll 1$ and $g \alpha L / c_{\mathrm{p}} \Delta T \ll 1$ are valid. Hence, density differences, except where they appear in terms with acceleration due to gravity, are negligible. As a result, we obtain a set of dimensionless equations:

$\nabla^{\prime} \mathbf{u}^{\prime}=0$,

$\mathbf{u}^{\prime} \nabla^{\prime} \mathbf{u}^{\prime}=-\nabla^{\prime} p^{\prime}+\frac{1}{\mathcal{R} e} \nabla^{\prime 2} \mathbf{u}^{\prime}+\frac{1}{\mathcal{F} r^{2}} \mathbf{e}_{\mathrm{z}}$,

$\nabla^{\prime} T^{\prime}=\frac{1}{\mathcal{R} e \mathcal{P} r} \nabla^{\prime 2} T^{\prime}+\frac{1}{\mathcal{J} a \mathcal{S} h} \nabla^{\prime 2} \varrho_{\mathrm{v}}^{\prime}$.

Here, $\nabla^{\prime}=1 / \ell \nabla, T^{\prime}=T / \Delta T, \mathbf{u}^{\prime}=1 / U \mathbf{u}, \varrho_{\mathrm{v}}^{\prime}=\varrho_{\mathrm{v}} / \rho$, and $p^{\prime}=p /\left(U^{2} \varrho\right)$, where $\ell$ represents the characteristic length, $\Delta T$ the characteristic temperature difference, and $U$ the characteristic velocity. Now, the system is characterised by 
means of five non-dimensional numbers. An overview of the characteristic numbers, their definition and interpretation can be found in Table 1, where $U_{\text {in }}$ is the mean inflow velocity, $D_{\mathrm{h}}$ is the hydraulic diameter, $L$ is the test section length, $\Delta \rho=\varrho_{\text {out }}-\varrho_{\text {in }}$ is the density difference between the outlet and the inlet, $\Delta T=T_{\mathrm{b}}-T_{\mathrm{f}}$ is the temperature difference between the mean bulk temperature $T_{\mathrm{b}}=0.5\left(T_{\text {in }}+T_{\text {out }}\right)$ and the cooling plate temperature, $\Delta \dot{M}_{\mathrm{v}}$ is the vapour mass transfer due to phase transition, $H$ is the height of the gap, $A_{\mathrm{f}}=L \times W$ is the area of diffusion and $\varrho_{\mathrm{v}}$ is the vapour density difference between the boundary layer above the cooling plate and the mean vapour density of the gap flow.

Based on this set of characteristic numbers (Table 1), the following concept of scaling is proposed.

\subsection{Concept of scaling}

A major objective of the present study is to determine the effect of two different insulation blankets on the heat transport and mass transfer due to phase transition in a laboratory experiment simulating real flight conditions. One requirement to guarantee the latter is that the dimensionless numbers, realised in the laboratory are similar to the numbers obtained for a real flight. Of course, for such a complex system, the scaling must be done with care. Hence, it is advisable to adjust parameters as little as possible. The parameters which can be varied are the volume flow of the air $\dot{V}$, the inflow velocity $U_{\text {in }}$, the inflow temperature $T_{\text {in }}$, the dew point of the air flow at the inlet $\Theta_{\text {in }}$, the vapour mass flow $\dot{M}_{\text {in }}$ and the temperature of the cooling plate $T_{\mathrm{f}}$ representing the fuselage temperature of an aircraft.

For the present study, the temperature of the cooling device, the air inflow temperature and the dew point temperature of the air inflow have to be adjusted to estimate the mass transfer and heat transport in case of realistic flight conditions. The temperature has to be adjusted due to technical restrictions. Our cooling unit does not provide the low temperature of the fuselage $T_{\mathrm{f}}=-35.0^{\circ} \mathrm{C}$ prevailing during cruise flight. In case of the laboratory experiments, only a temperature of $T_{\mathrm{f}}^{(1)}=-26.5^{\circ} \mathrm{C}$ is feasible. To obtain

Table 1 List of characteristic numbers including their definition and physical interpretation

\begin{tabular}{lll}
\hline Name & Definition & Physical interpretation \\
\hline Reynolds number & $\mathcal{R} e=\frac{U D_{\mathrm{h}} \rho}{\eta}$ & Inertia to viscous forces \\
Prandtl number & $\mathcal{P} r=\frac{\eta c_{\mathrm{p}}}{\lambda}$ & Viscous to thermal diffusion rate \\
Froude number & $\mathcal{F} r=\frac{U}{\sqrt{\Delta \rho / \rho g L}}$ & Inertia to gravitational forces \\
Jakobs number & $\mathcal{J} a=\frac{\Delta T c_{\mathrm{p}}}{H_{\mathrm{v}}}$ & Sensible to latent heat \\
Sherwood number & $\mathcal{S} h=\frac{\Delta \dot{\mathrm{M}}_{\mathrm{v}} H_{\mathrm{v}}}{A_{\mathrm{f}} D \Delta \rho_{\mathrm{v}}}$ & Mass transfer to mass diffusion \\
\hline
\end{tabular}

similitude, the temperatures were adjusted by $\delta T=+8.5^{\circ} \mathrm{C}$. In the following, the indices $(l)$ and $(r)$ denote the values for the laboratory and the real flight scenario, respectively. As a consequence, the total temperatures differ. Nevertheless, the characteristic temperature differences are similar for the real flight and for the laboratory experiments, since a similar Jacob number is obtained for both cases. However, the temperature adjustment results in different densities of the fluid for both cases. With the aim to reach similitude for the Reynolds number and Froude number, the volume flow is scaled by the factor $\varrho_{\text {in }}^{(\mathrm{l})} / \varrho_{\mathrm{in}}^{(\mathrm{r})}$. This scaling factor considers the lower ambient pressure during the flight. The Prandtl number is inherently similar. Finally, the scaling of the mass transfer due to phase transition must be addressed. For this purpose, an additional study $[18,19]$ was performed. The objective of the studies was to find out how the dew point differences between the inlet and the outlet $\Delta \Theta=\Theta_{\text {in }}-\Theta_{\text {out }}$ and thus the moisture transfer scale, if the absolute temperatures change and the characteristic temperature differences are constant. For the present configuration, it turned out that the dew point difference as well as the temperature difference $\Delta T=T_{\mathrm{m}}-T_{\mathrm{f}}$ are constant, while the absolute temperatures vary. As a result, the dew point of the inflow is adjusted in the same manner as the temperatures $\delta \Theta_{\mathrm{s}}=+8.5^{\circ} \mathrm{C}$. Based on these findings, the scaling concept of the mass flow is defined as follows.

For the present measurements, the vapour mass flow is determined by the dew point, the inflow temperature and the volume flow (for details see Sect. 3). The re-scaled dew point and inflow temperature at the gap inlet for realistic flight conditions are consequently $\Theta_{\text {in }}^{(\mathrm{r})}=\Theta_{\text {in }}^{(\mathrm{l})}-\delta \Theta_{\mathrm{s}}$ and $T_{\mathrm{in}}^{(\mathrm{r})}=T_{\mathrm{in}}^{(\mathrm{l})}-\delta T_{\mathrm{s}}$. Based on the re-scaled dew point $\Theta_{\text {in }}^{(\mathrm{r})}$ and air temperature $T_{\text {in }}^{(\mathrm{r})}$ at the inlet of the gap wind tunnel, the vapour pressure $p_{\mathrm{v}}^{(\mathrm{r})}$ is determined by means of the relations of Sonntag [20]. As a consequence, the corresponding vapour density $\varrho_{\mathrm{v}, \text { in }}^{(\mathrm{r})}$ is defined as:

$\varrho_{\mathrm{v}}^{(\mathrm{r})}=\frac{p_{\mathrm{v}}^{(\mathrm{r})}}{R_{\mathrm{v}} T^{(\mathrm{r})}}$

where $R_{\mathrm{v}}$ is the specific gas constant and the vapour mass flow $\dot{M}_{\mathrm{v}, \text { in }}^{(\mathrm{r})}$ at the gap inlet corresponds to:

$\dot{M}_{\mathrm{v}}^{(\mathrm{r})}=\varrho_{\mathrm{v}}^{(\mathrm{r})} \dot{V}$.

Furthermore, the re-scaled dew point at the outlet is:

$\Theta_{\text {out }}^{(\mathrm{r})}=\Theta_{\text {in }}^{(\mathrm{r})}+\left(\Theta_{\text {in }}^{(\mathrm{l})}-\Theta_{\text {out }}^{(\mathrm{l})}\right)$.

Since $\Delta T^{(\mathrm{l})}=\Delta T^{(\mathrm{r})}$, the re-scaled temperature at the outlet is:

$T_{\text {out }}^{(\mathrm{r})}=2\left(\Delta T^{(\mathrm{l})}+T_{\mathrm{f}}^{(\mathrm{r})}\right)-T_{\mathrm{in}}^{(\mathrm{r})}$. 
The corresponding vapour density $\varrho_{\mathrm{v}, \text { out }}^{(\mathrm{r})}$ and mass flow $\dot{M}_{\mathrm{v}, \text { out }}^{(\mathrm{r})}$ at the outlet is derived from Eqs. (11) and (12). Finally, the re-scaled mass transfer due to phase transition is:

$\Delta \dot{M}_{\mathrm{v}}^{(\mathrm{r})}=\dot{M}_{\mathrm{v}, \text { in }}^{(\mathrm{r})}-\dot{M}_{\mathrm{v}, \text { out }}^{(\mathrm{r})}$

For the present configuration, the vapour density gradient $\Delta \rho_{\mathrm{v}}$ between the bulk and the layer between fuselage and the insulation blanket is determined by the mass transfer due to phase transition $\Delta \dot{M}_{\mathrm{v}}$. Moreover, the vapour density gradient depends linearly on the mass transfer $\Delta \dot{M}_{\mathrm{v}}$. Hence, we can assume that the ratio of the mass transfer and vapour density $\Delta \dot{M}_{\mathrm{v}} / \Delta \varrho_{\mathrm{v}}$ is similar for the real flight and for the laboratory conditions. As a result, the Sherwood number is similar as well. The here introduced concept of scaling provides similitude between real flight tests and laboratory measurements. Based on this concept, the results of the laboratory measurements are re-scaled. Hence, in the following, all results are related to the re-scaled values representing the estimated heat transport and mass transfer for the realistic flight conditions.

Concluding, we briefly discuss the limitations and restrictions as well as the advantages of the above-described scaling. Inherently, an important advantage of the concept is that measurements can be performed in a laboratory with significantly reduced technical and monetary effort in comparison with flight tests. Furthermore, the non-dimensional characterisation allows to compare results based on the dimensionless numbers whether the parameter range of the physical properties are similar or not. However, we are aware of the limitation and restrictions of the concept. One problem is the fact that the freezing point does not scale. In comparison with an unscaled flight scenario, a temperature adjustment of $\delta T=+8.5 \mathrm{~K}$ for the scaled laboratory configuration has the consequence that during the climbing period, the water on the cold surface starts to freeze 10 min earlier and during the descent period the frozen layer starts to melt 10 min later. As a consequence, more condensation water freezes on the inner surface of the fuselage resulting in a thicker ice layer. The higher layer is an additional insulation and leads to a lower heat transfer on the cold surface and thus to a lower mass transfer due to phase transition. An exact quantification of the additional water mass due to phase transition is not possible. However, for the present study, an estimation of the potential increase of the total water mass is less than $4 \%$ of the total water mass. Another aspect, which is not take into account for the concept of scaling, is the effect of the temperature adjustment on the sorption behaviour of the insulation blankets. The sorption of porous media is characterised by means of the sorption isotherm, which is a function of temperature and relative humidity. An estimation, based on the technical report [21], shows that the scaling of the temperature leads to a variance of less than $1 \%$ of the water mass in the blanket. Regarding the relative humidity, no impact is expected since the relative humidity is similar for the real flight scenario and the laboratory setup. Hence, the temperature and the dew point adjustments should have no significant effect on the maximum water intake of a porous medium.

\section{Experimental setup}

The experimental studies of heat transport and mass transfer due to phase transition for an active gap flow were performed in a gap wind tunnel. It is a strongly simplified generic configuration, representing the gap between the fuselage and the cabin wall in an aircraft. The gap wind tunnel is a vertically orientated, cooled from one side duct with a rectangular cross-section. Figure 2 depicts the supply air system, a sketch of the gap wind tunnel, and the corresponding boundary conditions and dimensions.

A flowchart summarising the components of the supply air system and the test facility (left), a sketch of the gap wind tunnel (right), together with the corresponding boundary conditions and dimensions (bottom) of the setup is depicted in Fig. 2. The sketch in Fig. 2 (right) reflects the three sections of the wind tunnel. An inlet section with a length of $L_{\text {in }}=1500 \mathrm{~mm}(30 \times H)$, guarantees a fully developed and homogeneous inflow at the inlet of the test section. Furthermore, the test section is equipped with an outlet section at the end. The length of the outlet is $L_{\text {out }}=500 \mathrm{~mm}$. It provides a homogeneous and undisturbed outflow. All side walls are thermally insulated to obtain nearly adiabatic boundary conditions. The length of the test section amounts to $L_{\mathrm{t}}=2050 \mathrm{~mm}$. One side of the test section is isothermally cooled, and the other side walls are insulated. The dimensions of the gap wind tunnel represent a segment corresponding to the gap between the fuselage and the cabin wall of an aircraft. Two different configurations were studied, one with and one without insulation blankets. One blanket is made of fibreglass and complies with the standard insulation blankets nowadays used as primary insulation in an aircraft. The other one is an insulation blanket made of melamine resin foam with the type designation Basotect UF. Melamine resin foam consists of a formaldehyde-melamine-sodium bisulfite copolymer and is open-celled duromere. Both insulation blankets have the same state of the art foil. The insulation blankets have a height of $H_{\mathrm{i}}=50 \mathrm{~mm}$ and the width as well as the length correspond to those of the wind tunnel. In case of the configuration with insulation, the total height of the duct is $H=100 \mathrm{~mm}$ and for the configuration without insulation the height is $H=50 \mathrm{~mm}$. Hence, the height of the gap for the air flow is $H=50 \mathrm{~mm}$ for all three configurations. Furthermore, both insulation blankets are covered 
Fig. 2 Left side: flowchart of the system consisting of the supply air system, the gap wind tunnel and the measurement components. Right side: schematic sketch of the gap wind tunnel. The tables list the dimensions and the boundary conditions

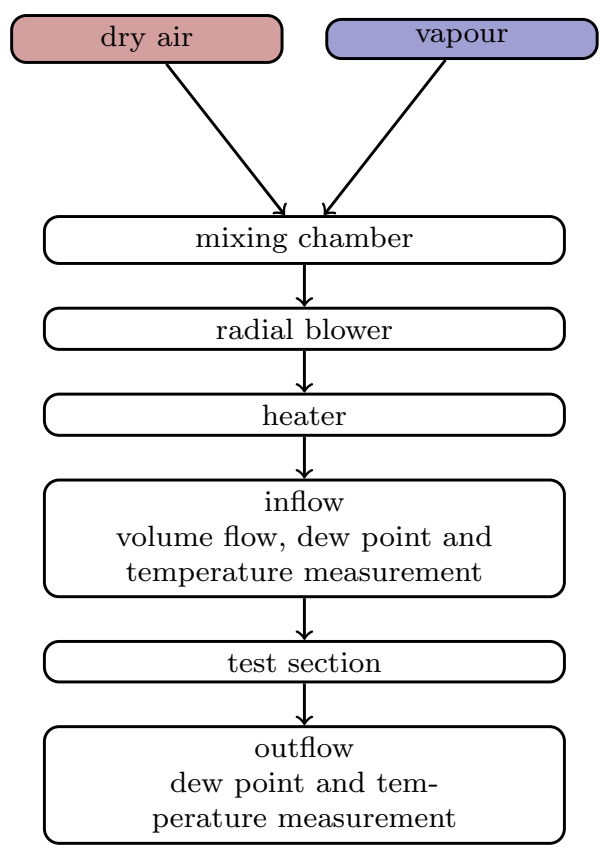

\begin{tabular}{ll}
\hline \multicolumn{2}{c}{ Dimensions } \\
\hline length test section & $L=2050 \mathrm{~mm}$ \\
length inflow section & $L_{\text {in }}=1500 \mathrm{~mm}$ \\
length outflow section & $L_{\text {out }}=500 \mathrm{~mm}$ \\
width & $W=533 \mathrm{~mm}$ \\
height & $H=50 \mathrm{~mm}$ \\
\hline \hline
\end{tabular}

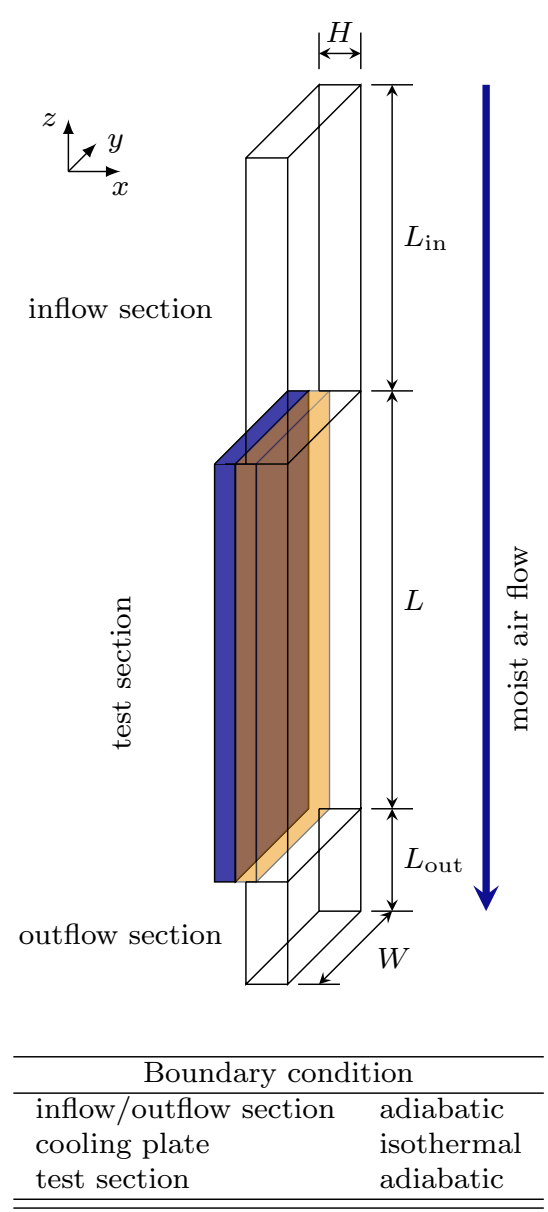

by a foil as used for standard insulation blankets without ventilation holes.

The supply air system consists of an air dryer, a vapour generator, a radial blower and a volume flow meter with an accuracy of $1 \%$ of the measurement value. The vapour generator works on the basis of ultrasonic vaporisers generating a saturated vapour in a closed box. In addition, the box is equipped with an speed-controlled fan. Depending on the fan speed, a defined vapour mass is blown into the mixing chamber. In the chamber, the vapour and the dried air are mixed. Moist air is sucked in by a radial blower to generate an air flow with a constant volume flow. Afterwards, the air flow is heated by a heater.

With the objective to determine the convective heat transport and mass transfer due to phase transition, the test facility is equipped with numerous resistance temperature detectors (RTD) made of platinum and capacitive humidity sensors (CHS). The function of the temperature sensors and the humidity sensors in the present configuration is twofold. Besides the determination of the inflow conditions, the sensors are used to control the inflow humidity and temperature. The RTDs corresponds to the sensor class DIN B 1/3 which provides a measurement accuracy for the present parameter range of $\sigma_{T} \approx 0.11 \mathrm{~K}$. Temperature measurements are performed in the inlet and outlet of the test section as well as in the cooling plate. 23 RTDs are placed, homogeneously distributed, in the cooling plate to measure and control the simulated fuselage temperature $T_{\mathrm{f}}$. The plate consists of aluminium with a system of pipes flown through by a liquid cooled or heated by a device with a heating power of $17 \mathrm{~kW}$ and a cooling power of $5 \mathrm{~kW}$. Based on this configuration, we are able to provide isothermal boundary conditions with a spatial temperature distribution of less than $0.5 \mathrm{~K}$. Three temperature sensors are installed in the supply air system at the beginning of the inlet section and shortly behind the outlet section of the wind tunnel, respectively. In addition, seven temperature sensors are positioned in the vicinity of the test facility to determine the ambient temperature. Based on the measurement of this temperature and the mean bulk air temperature $T_{\mathrm{b}}=0.5\left(T_{\text {in }}+T_{\text {out }}\right)$, the heat transfer through the insulated side wall $\dot{Q}_{\mathrm{sw}}$ is calculated.

The capacitive humidity sensors have the type designation Sensirion SHT75 with a measurement accuracy for the relative humidity of $1.8 \%$. Ten humidity sensors are placed in the supply air system and in a mixing chamber behind the outlet section, respectively. To obtain a higher 
accuracy prior to each measurement, the capacitive humidity sensors are calibrated by means of two dew point mirrors. Each of the dew point mirrors has a dew point accuracy of $0.1 \mathrm{~K}$. Hence, we obtain a linear relation between $\Theta_{C H S}=a \Theta_{D P M}+b$, the capacitive sensors and the dew point mirrors. In addition, the offset of the mean dew point temperature at the inlet and outlet section is determined. By means of this calibration procedure, the uncertainty of the dew point difference $\Delta \Theta$ between the inflow and the outflow dew point is less than $0.1 \mathrm{~K}$ for all measurements.

Based on the supply air system, we are able to provide well-defined flow conditions of moist air regarding volume flow, temperature and humidity. In addition, the temperature and humidity sensors allow to determine the global heat flux and mass transfer due to phase transition. The mass transfer due to phase transition is calculated by the mass flow difference of the vapour

$\Delta \dot{M}_{v}=\dot{M}_{\mathrm{v}}^{(\text {in })}-\dot{M}_{\mathrm{v}}^{(\text {out })}$

where $\dot{M}_{\mathrm{v}}^{\text {(in) }}$ and $\dot{M}_{\mathrm{v}}^{\text {(out) }}$ denote the vapour mass flow at the test section inlet and outlet, respectively. For vapour mass transfer, the calculated error, based on a error propagation including the calibration error of the CHS, the error of the volume flow measurement and the error of the temperature measurements, is amounts to approximately four percent of the corresponding $\Delta \dot{M}_{v}$ for all measurements. Detailed information about the error is given in the result section.

The global heat flux is given by

$\dot{Q}_{\mathrm{t}}=\dot{M}_{\mathrm{air}} c_{\mathrm{p}}^{\mathrm{air}} \Delta T_{\mathrm{t}}-\dot{Q}_{\mathrm{sw}}$.

Here, $\dot{M}_{\text {air }}$ labels the mass flow of the moist air, $c_{\mathrm{p}}^{\text {air }}$ the specific heat capacity, $\dot{Q}_{\mathrm{sw}}$ the heat loss through the side walls, and $\Delta T_{\mathrm{t}}$ the temperature difference between mean temperature at the inlet $\Delta T_{\text {in }}$ and the mean temperature at the outlet $\Delta T_{\text {out }}$. The fluid and vapour properties required to determine the mass transfer due to phase transition and the heat flux are obtained from equations which take into account the molar mass relation of the air vapour mixture. The latter are given in Tsilingeris [22].

\section{Mass transfer and heat transport}

The effect of condensation, icing and evaporation on the heat transport and mass transfer was studied for the case of displacement ventilation based on the so-called flight scenario Alaska. The boundary conditions of the Alaska scenario are summarised in [18, 23]. The Alaska flight scenario includes four periods: climb, cruise, descent and ground. The duration of the climb and that of the descent is $30 \mathrm{~min}$, respectively, the cruise is $180 \mathrm{~min}$ long, and the ground period lasts $45 \mathrm{~min}$. Consequently, the total time is $285 \mathrm{~min}$. The temperature and the humidity parameters for each period are listed in Table 2. In Table 2, the unscaled flight boundary conditions are indicated in brackets and the values used for the experiments, adjusted on the basis of the concept of scaling (Sect. 2.2), are written without brackets. Here, we would like to point out that the temperature and the humidity reflect generic profiles compared to the much more complex profiles of a real flight.

The system is determined by the following four boundary conditions: volume flow $\dot{V}$, inflow temperature $T_{\text {in }}$, temperature of the fuselage $T_{\mathrm{f}}$ and humidity of the moist air at the inlet of the gap. For all flight periods, the volume flow of the moist air $\dot{V}=17.0 \mathrm{l} / \mathrm{s}$, which corresponds to the air exchange rate of one segment with a width of $W=0.533 \mathrm{~m}$ with an inflow temperature $T_{\text {in }}=32.5^{\circ} \mathrm{C}$, is constant. Furthermore, the two boundary conditions fuselage temperature and dew point temperature at the inlet of the test section are plotted in Fig. 3. Here and in the following figures, the singleflight periods are separated by the dashed lines. In case of the flight scenario Alaska, the scaled fuselage temperature (Fig. 3a) on the ground is $T_{\mathrm{f}}=-1.5^{\circ} \mathrm{C}$ and the dew point temperature is $\Theta_{\text {in }}=-1.2^{\circ} \mathrm{C}$. This corresponds to a relative humidity of $\mathrm{RH}=10.6 \%$. During the climb, the temperature decreases linearly to $T_{\mathrm{f}}=-26.5^{\circ} \mathrm{C}$, while at the same time the dew point temperature increases linearly up to $\Theta_{\text {in }}=11.1^{\circ} \mathrm{C}$. During the cruise, the fuselage temperature and the dew point are constant. In the period of descent, the fuselage temperature increases linearly, and the dew point temperature decreases. At the end of this period, both temperatures correspond to the temperature on ground. Based on this flight scenario, the mass transfer and heat transport
Table 2 List of the scaled and real flight (brackets) boundary conditions for the scenario Alaska

\begin{tabular}{llllll}
\hline & TOT $(\mathrm{h}: \min )$ & $T_{\mathrm{f}}\left({ }^{\circ} \mathrm{C}\right)$ & $T_{\text {in }}\left({ }^{\circ} \mathrm{C}\right)$ & $R H_{\text {in }}(\%)$ & $\Theta_{\text {in }}\left({ }^{\circ} \mathrm{C}\right)$ \\
\hline Climb & $0: 30$ & Linear & Linear & Linear & Linear \\
Cruise & $3: 30$ & $-26.5(-35.0)$ & $32.5(24.0)$ & $26.2(25)$ & $11.13(2.63)$ \\
Descent & $4: 00$ & Linear & Linear & Linear & Linear \\
Ground & $4: 45$ & $-1.5(-10.0)$ & $32.5(24.0)$ & $10.6(10)$ & $-1.21(-9.71)$ \\
\hline
\end{tabular}

Here, TOT is the total time as a function of the different stages of flight, $T_{\mathrm{f}}$ the temperature of the fuselage, $R H_{\text {in }}$ the relative humidity and $\Theta_{\text {in }}$ the dew point temperature at the inlet of the test section 
Fig. 3 Flight scenario Alaska: a temperature of isothermal boundary representing the fuselage $T_{\mathrm{f}}$ and $\mathbf{b}$ the dew point temperature $\Theta_{\text {in }}$ at the inlet of the test section

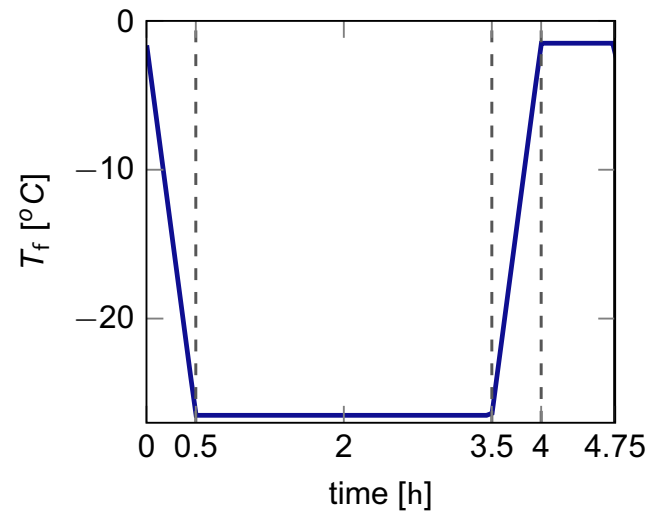

(a) fuselage temperature

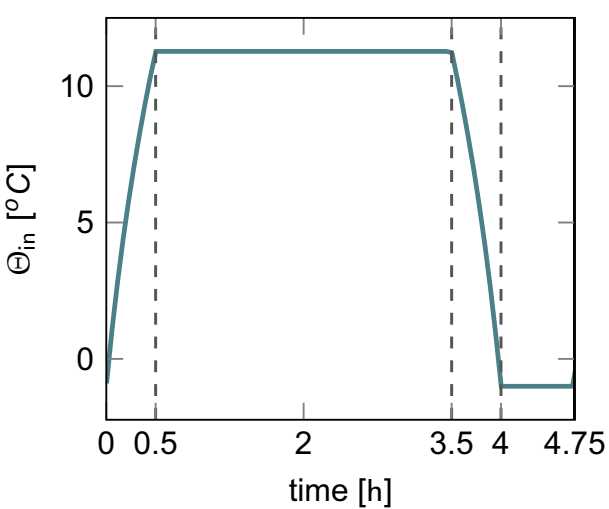

(b) dew point temperature for an active gap flow were studied for two different insulation blankets and without any insulation material. Furthermore, with the aim to identify the long-term impact on the mass transfer and heat transport resulting from the water accumulation in the insulation blankets, measurements were performed for a sequence of five scenarios. Due to the much higher mass transfer in the case without insulation, measurements were performed for only four scenarios.

Figure 4 shows the mass transfer due to phase transition $\Delta \dot{M}$ as a function of time for a sequence of five flight
Fig. 4 Vapour mass transfer due to phase transition and boundary conditions as a function of time for the sequence of five flight scenarios: (1) + (2) vapour mass transfer for the measurement with insulation blankets and the corresponding relative error, (3) vapour mass transfer for the reference case without insulation, (4) temperature of the cooled surface, and (5) dew point temperature at the inlet

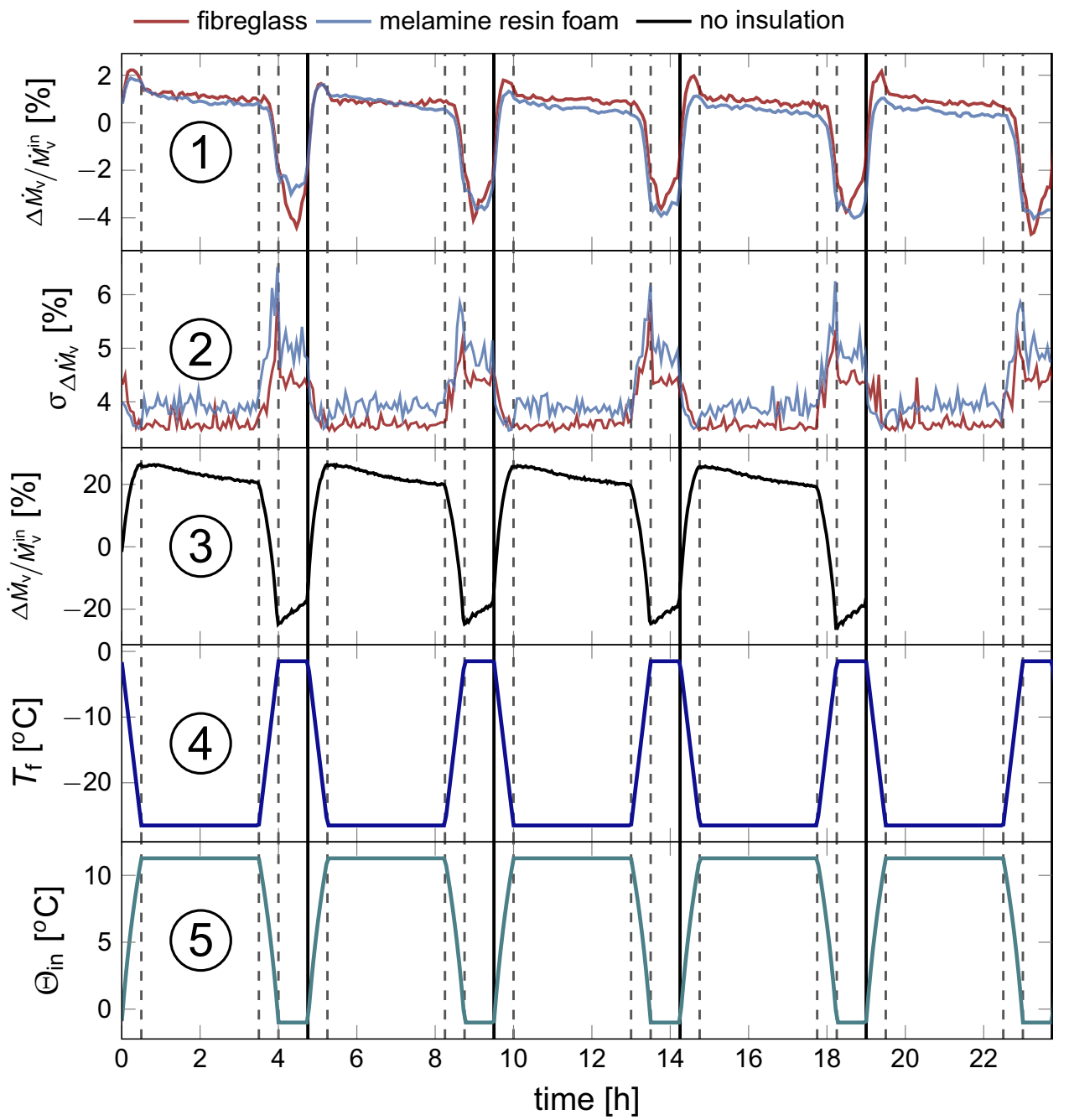


scenarios. In total, the measurement time amounts to $T=1425$ min with a mean passing time of the air through the channel of $\tau=3.2 \mathrm{~s}$. The four flight periods are indicated by the dashed lines, whereas a single flight is separated by the black lines. Figure 4-4, -5 depict the corresponding boundary conditions: temperature of the fuselage $T_{\mathrm{f}}$ and $\mathrm{d}^{* *}$ dew point temperature at the inlet of the gap $\Theta_{\text {in }}$. Figure 4$1,-3$ reflect the mass flow as a result of the phase transition $\Delta \dot{M}_{\mathrm{v}}$ normalised with the incoming vapour mass flow at the inlet of the gap $\dot{M}_{\text {in }}$ in percentage. The results obtained with fibreglass (red) and melamine resin foam (blue) are plotted in Fig. 4-1. The mass transfer in the case without insulation (black) is also shown in Fig. 4-3 for comparison. Please note that mass transfer due to condensation has a positive sign and evaporation a negative one. In addition, Fig. 4-2 illustrates the relative error $\sigma_{\Delta \dot{M}_{\mathrm{v}}}$ of $\Delta \dot{M}_{\mathrm{v}} / \dot{M}_{\mathrm{v}}^{\text {in }}$ in percentage. On average, the measurement error for the fibre glass blanket is $3.9 \% \times \Delta \dot{M}_{\mathrm{v}} / \dot{M}_{\mathrm{v}}^{\text {in }}$ and in case of the melamine resin foam it is $4.2 \% \times \Delta \dot{M}_{\mathrm{v}} / \dot{M}_{\mathrm{v}}^{\text {in }}$. Regarding the reference measurement with no insulation, the mean error (not shown in Fig. 4) is $3.4 \% \times \Delta \dot{M}_{\mathrm{v}} / \dot{M}_{\mathrm{v}}^{\text {in }}$.

The cases with the two insulation materials and without insulation show a similar behaviour regarding the mass transfer. During the climb, the humidity increases and the temperature of the surface of the cooling plate decreases. As a consequence, the temperature on and above the cooled surface falls below the dew point temperature, and water condensates. In the case with insulation materials, the maximum of the heat transfer is observed already during the climb period. In contrast, for the case without insulation, the mass transfer reaches its maximum at the beginning of the cruise. Moreover, during this flight period the mass flow decreases, even though the fuselage temperature as well as the incoming vapour mass flow remain constant. This effect is even more pronounced in the case without insulation. The decreasing mass flow during the cruise is caused by the growing layer of frozen water on the cooling plate. However, the water does not freeze to a compact ice layer. Rather, a layer of frozen water comparable with rime (see also Fig. 6) is formed. This fact is of vital interest, since the layer of rime has a much higher heat resistance compared to a compact ice layer. As a result of the growing thickness of the rime layer on the cooling plate, the thermal resistance increases. Consequently, the heat transport between the air flow and the cooling plate decreases. Since the mass transfer due to phase transition is proportional to the heat transport, the mass flow decreases with increasing layer thickness. On the other hand, in the period of descent, the humidity decreases, while the fuselage temperature increases. As a result, the mass flow due to condensation decreases drastically until the frozen layer starts to melt and the water evaporates. However, the change of mass transfer in the case without insulation starts directly with the beginning of the descent. With insulation, the higher thermal resistance phase transition to set in later. Finally, on the ground, the rime layer melts further and the water evaporates.

Although the qualitative behaviour of the mass flow as a function of the periods is similar, there are significant quantitative differences for the cases with and without insulation blankets and also between the cases with the two different insulation blankets. Figure 4-1, -2 disclose that the mass flow of vapour $\Delta \dot{M}_{\mathrm{v}}$ due to phase transition is a magnitude higher without insulation than with insulation. For the period of condensation, the mass transfer $\Delta \dot{M}$ amounts to $20 \%$ of the incoming vapour mass flow $\dot{M}_{\text {in }}$ without insulation. With insulation, the maximum mass flow amounts to approximately $2 \%$ of the vapour mass flow at the gap inlet. Although, this is not surprising, it underlines, however, the need for an effective insulation on the inner side of the fuselage to avoid strong ice or rime agglomerations in the gap between fuselage and cabin. This is even more important in a real flight situation where the ambient temperature is below the freezing point on ground and the danger of a total closure of the gap exists.

Figure 5 depicts the cumulative mass:

$M_{\mathrm{H}_{2} \mathrm{O}}=\int_{T} \Delta \dot{M} \mathrm{~d} t$,

of water in the gap as a function of time. Here, $T$ is the time period and $\Delta \dot{M}$ the mass transfer due to phase transition. The corresponding confidence interval of $M_{\mathrm{H}_{2} \mathrm{O}}$, calculated by error propagation, is depicted by the coloured area. Without insulation, the mass corresponds to the mass of the rime layer on the cooling device. With insulation, the main part of the water mass also corresponds to the rime layer. However, a smaller part is bound in the insulation blankets. Figure 5 (top) shows the total mass for the configurations with insulation blanket in comparison with Fig. 5 (bottom) without insulation. Without insulation, the total water mass at the end of four flights is approximately $M_{\mathrm{H}_{2} \mathrm{O}} \approx 1700 \mathrm{~g}$ in contrast to the cases with insulation where the total water mass is 40 times less in case of the fibreglass and even 80 times less for the melamine resin foam. Moreover, the increase in the water mass for each flight is nearly constants $\delta M_{\mathrm{H}_{2} \mathrm{O}}=465(1)$ without insulation. Furthermore, the mass ratio of water that evaporates $M_{\mathrm{H}_{2} \mathrm{O}}^{(-)}$to the vapour that condensates $M_{\mathrm{H}_{2} \mathrm{O}}^{(+)}$during one period is $M_{\mathrm{H}_{2} \mathrm{O}}^{(-)} / M_{\mathrm{H}_{2} \mathrm{O}}^{(+)}=10.3(4) \%$. This means that for one flight period, merely $10 \%$ of the water mass evaporates during the descent and on ground. Additionally, Fig. 4 reveals that the mass flow rate decreases during the ground phase. In summary, without insulation, we observe a constant increase in water mass, which forms a rime layer on the cooling plate. If we assume a density of $300 \mathrm{~kg} / \mathrm{m}^{3}$ for the ice on the surface for the measurements without insulation the rime layer would have an averaged 
Fig. 5 Cumulative sum of the condensate water as solid or liquid matter on the surface of the cooled boundary or bound to the insulation blanket as a function of time in case of insulation (top) and without insulation (bottom). The coloured areas reveal the corresponding confidence interval

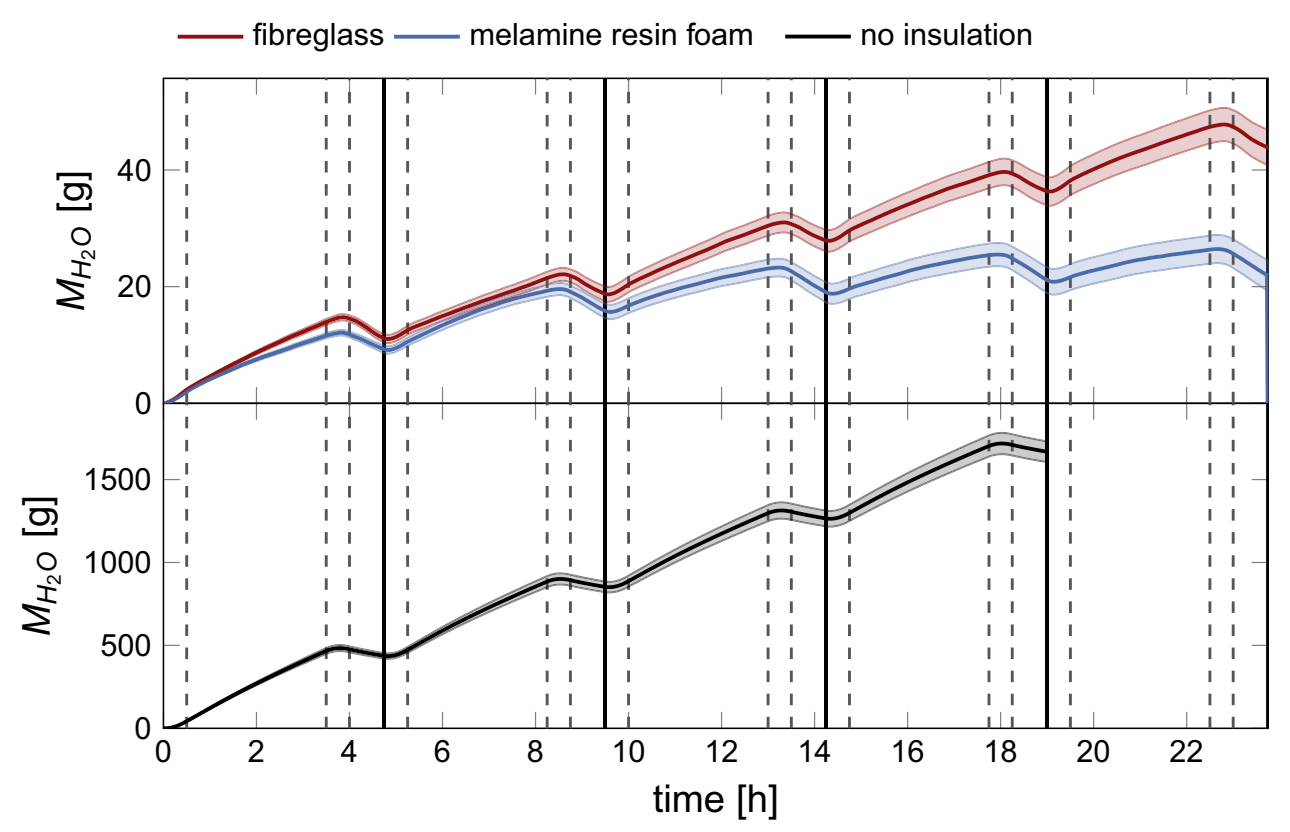

height of approximately $5 \mathrm{~mm}$. However, the rime layer height is not homogeneously distributed. It is supposed that at the beginning of the gap the vapour mass transfer is higher than at the end of the gap. Hence, the rime layer has its maximum height at the beginning of the gap and the risk of a total closure, in particular, at the beginning of the gap, cannot be ruled out.

Since the main objective of the present work is to analyse the impact of the two insulation materials on the mass transfer and heat transport, the following discussion focuses on the differences observed during the experiments with the two insulation blankets made of fibreglass and melamine resin foam. To improve the understanding of the physical processes taking place in the gap, the growth of the rime layer as a function of time is illustrated in Fig. 6. The photographs present the cross-section of the gap equipped with a fibreglass insulation blanket. To obtain a better view of the area between the cooling plate and the insulation, the blanket was folded back on the right side. This area is highlighted by the red box. For the measurements of the mass transfer and heat transport, the blankets were accurately fixed with tape over the whole width. The photographs are numbered consecutively, and the corresponding time stamp is provided on the right side of each photograph. Picture no. (1) reveals the state at $t=0 \mathrm{~min}$ i.e. at the beginning of the climb. During the climb (photograph (2) and (3)), the rime layer is becomes bigger. The layer of frozen water grows even further during the cruise (photograph (4)-(15)) until the maximum height of the rime layer is reached at half time of the descent, as illustrated in photograph (16). Afterwards, the rime layer starts to melt and the water evaporates. This leads to a vapour-pressure difference between the air flow above the insulation and the layer above the cooling plate. Hence, vapour diffuses through the insulation blanket, while water remains in the blanket. At the end of the ground period (photograph no. (19)), the layer of frozen water between the cooling plate and the insulation blanket seems to be totally evaporated.

An analysis of the mass transfer (Fig. 4 (1)) indicates that the mass transfer is similar for both insulation materials for the first two flights. For the following flights, the mass transfer due to condensation decreases in case of the melamine resin foam. As a result, we observe a weaker total mass increase in water with ongoing flights. How much the total mass differs is depicted in Figs. 5 (top) and 7a. Figure 5 (top) illustrates the total mass of water in the test section. In particular, with the beginning of the third flight, we observe a clear elevated mass increase in water in case of the fibreglass (red). Hence, after five flights the total mass for the melamine resin foam corresponds to twice the mass obtained for the fibreglass. Furthermore, the total water mass increases almost linearly for the fibreglass (red) for all five flights, while the total water mass is nearly constant for the last three flights for the melamine resin foam (blue).

The corresponding mass increase for the individual flights $\delta M_{\mathrm{H}_{2} \mathrm{O}}$ as a function of the flight number is illustrated in Fig. 7a. It is found that the mass increase during the two first flights differs by approximately $10 \%$ between the cases with the two insulation blankets. Beginning with the third flight, the total mass increase per flight decreases almost linearly in case of the melamine resin foam, while the mass increase remains almost constant for the fibreglass. During the fifth flight, the mass increase in case of the melamine resin foam is $\delta M_{\mathrm{H}_{2} \mathrm{O}}<1 \mathrm{~g}$, and the mass increase is eight times higher 
Fig. 6 Photographs of the ice layer between the insulation blanket and the cooling plate as a function of time for a single flight, including climb, cruise, descent and ground period. The photographs show the end of the test section. The photographs are numbered chronologically, and the corresponding time stamp is placed on the right side of each photograph

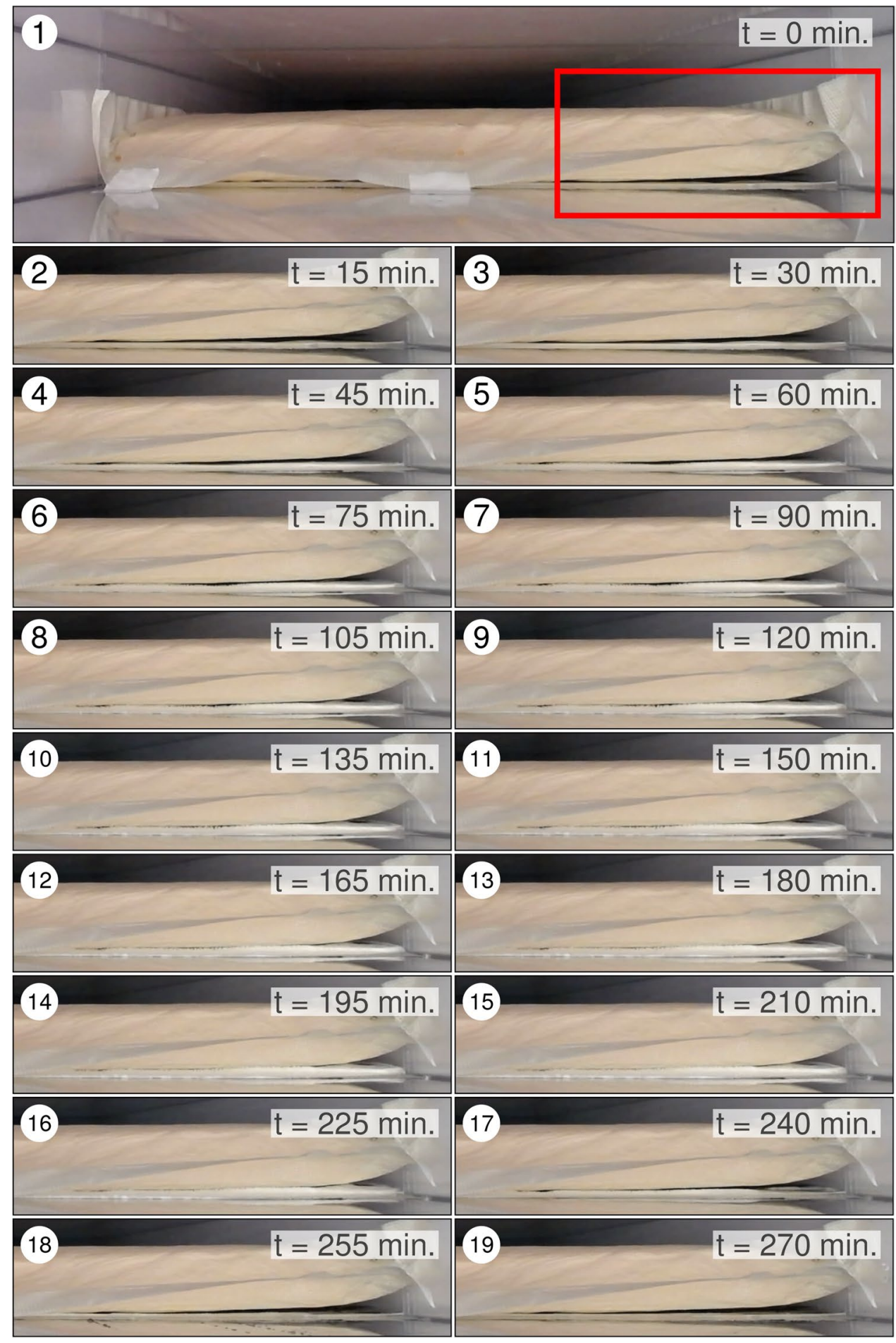

for the fibreglass. The reason for this difference are the different structure of the insulation materials. While fibreglass blankets consists of fibres, the melamine resin foam is an open-celled duromere. The melamine resin foam with its open-celled structure has a restricted capacity of water retention. As a consequence, at the end of the second flight, the cells are almost completely filled with water and less additional condensation occurs in the insulation material. Furthermore, nearly the total process of condensation takes places directly on the cooled plate or in the layer between the insulation blanket and the cooling plate. Since the insulation material is almost saturated with water, a diffusive mass transfer from the region of air flow into the region above the cooling plate is also blocked. As soon as the melamine 
Fig. 7 a Total mass increase in condensate water during a flight as a function of the flight number. $\mathbf{b}$ Mass ratio of water that evaporates to the mass that condensates

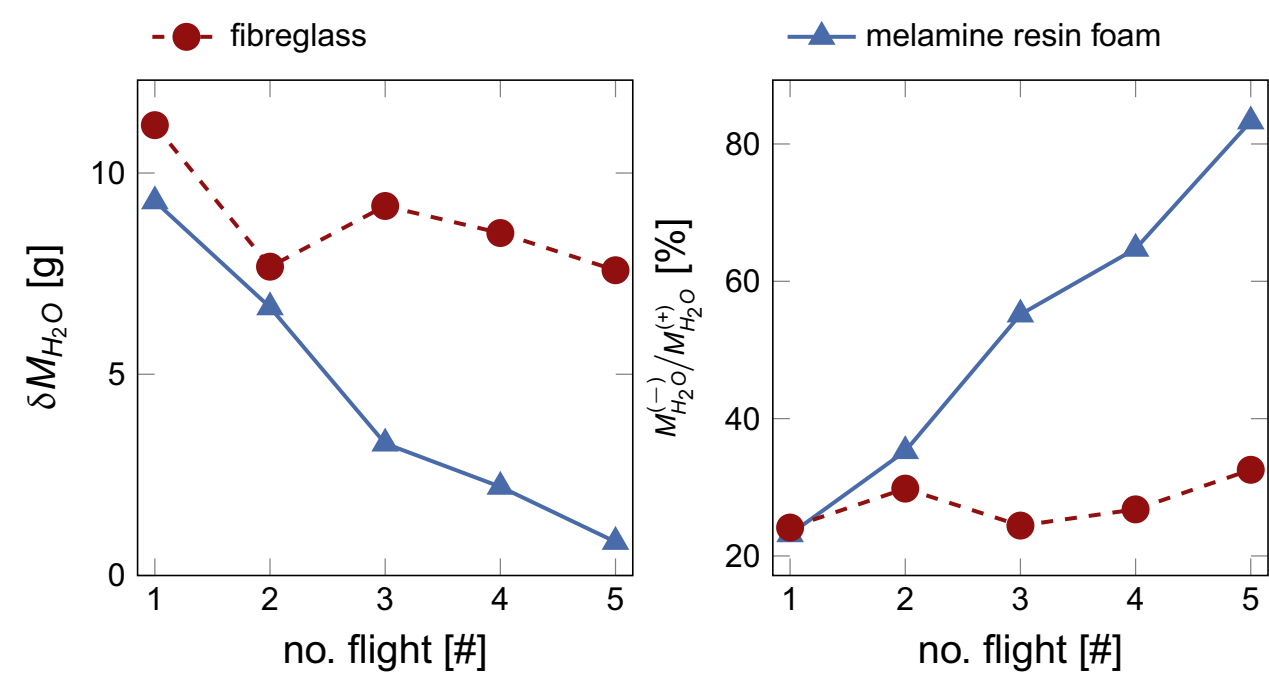

(a) total mass increase

(b) mass ratio evaporation to condensation resin foam blanket is saturated with water, a significantly lower condensation rate is observed. Of course, condensation can occur in the bulk region. However, in this region, the temperature is always above the dew point and there is no condensation. In contrast, a significant part of the blanket made of fibreglass consists of air. Hence, the mass of water which is embedded in the insulation blanket is much higher. As a consequence, a higher mass transfer due to diffusion through the layer above the cooled plate develops leading to a higher condensation rate.

Besides the process of condensation, significant differences are also found for the process of evaporation. Figure 7 depicts the percentage of water mass $M_{\mathrm{H}_{2} \mathrm{O}}^{(+)}$, which evaporates during the different flights. During the first two flights, the percentage of water which evaporates is again similar for both materials. For these two flights, the main part of the water is embedded in the insulation blankets. During the first and second flight of the fibreglass case, $76 \%$ and $70 \%$ of the water mass $M_{\mathrm{H}_{2} \mathrm{O}}^{(+)}$, which condensates during a flight, remain in the insulation blanket. The percentage of the remaining water mass in case of the melamine resin foam is $77 \%$ for the first flight and $66 \%$ of the total water mass transfer for the second flight, respectively. Starting with the third flight, the difference of the mass ratio between the two insulation blankets becomes evident. In case of the melamine resin foam, the mass of water which evaporates again during a flight increases linearly. For the fifth flight, $83 \%$ of the water $M_{\mathrm{H}_{2} \mathrm{O}}^{(+)}$ evaporate during the descent and ground period. In contrast, in case of the fibreglass, the percentage of the water mass which evaporates is almost constant $M_{\mathrm{H}_{2} \mathrm{O}}^{(-)} / M_{\mathrm{H}_{2} \mathrm{O}}^{(+)}=28(3) \%$ for all flights. As already mentioned above, with the beginning of the third flight, the melamine resin foam is almost saturated with water. Consequently, starting with the third flight, condensation and evaporation primarily take place in the insulation blanket on the side facing the air flow in the gap. However, here, the fluid temperature is above the dew point for nearly the whole time. This has two effects. First, with increasing flight number, the mass of water which condensates decreases significantly (Fig. 7a). Second, with increasing flight number, the main part of the water mass which condensates during the climb and the cruise evaporates during the descent and on ground (see Fig. 7). In the case of the fibreglass, the constant mass increase and the constant evaporation rate indicate that even after five flights the blanket is not saturated with water.

With the objective to identify differences in the behaviour of mass transfer due to phase transition for the two insulation materials, the mass increase during the two flight periods climb and cruise will be analysed in the following. Figure 8 shows the ratio of the mass increase in water to the total mass increase for a single flight in percentage for the climb $M_{\mathrm{cl}}^{(+)} / M_{\mathrm{t}}^{(+)}$(Fig. 8a) and cruise $M_{\mathrm{cr}}^{(+)} / M_{\mathrm{t}}^{(+)}$(Fig. 8b) as a function of the flight number. In case of the climb, two effects could be identified. The first effect is that for both insulation materials, the mass increase ratio $M_{c l}^{(+)} / M_{\mathrm{t}}^{(+)}$is significantly higher for the first flight compared to the subsequent flights. The reason is that the insulation is already dry again before the measurement begins. Consequently, the capacity to embed water in the insulation materials is higher than for the later flights. The second effect is that for the first three flights, the ratio $M_{\mathrm{cl}}^{(+)} / M_{\mathrm{t}}^{(+)}$is similar for both insulation blankets. However, for the fourth and fifth flight differences between the two insulation materials are observed. In the case of the fibreglass, the ratio $M_{\mathrm{cl}}^{(+)} / M_{\mathrm{t}}^{(+)}$is almost constant for flights $2-5$, while the ratio decreases for the melamine resin foam. This underlines the above-discussed observation that the melamine resin foam blanket is already saturated 
Fig. 8 a Ratio of mass increase during the climb $M_{\mathrm{cl}}^{(+)}$to the total mass increase $M_{\mathrm{t}}^{(+)}$for each individual flight as a function of the flight number. b Ratio of mass increase during the cruise $M_{\mathrm{cr}}^{(+)}$to the total mass increase $M_{\mathrm{t}}^{(+)}$for each individual flight as a function of the flight number

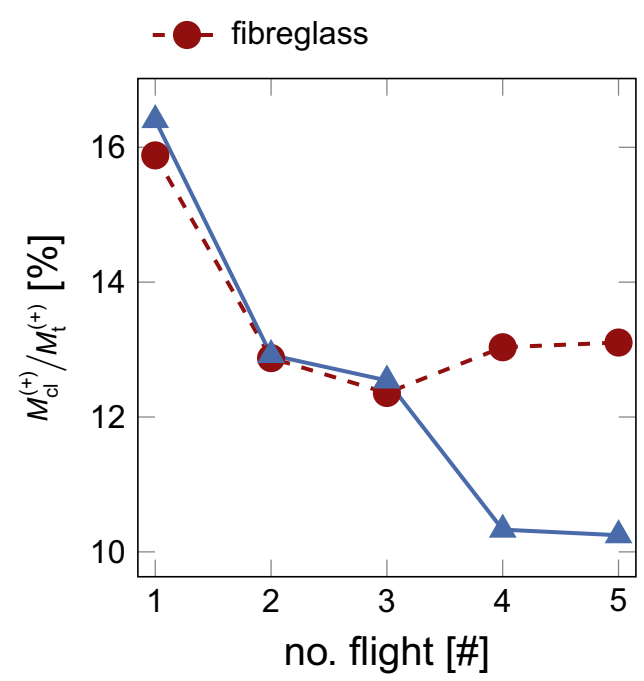

(a) mass ratio climb

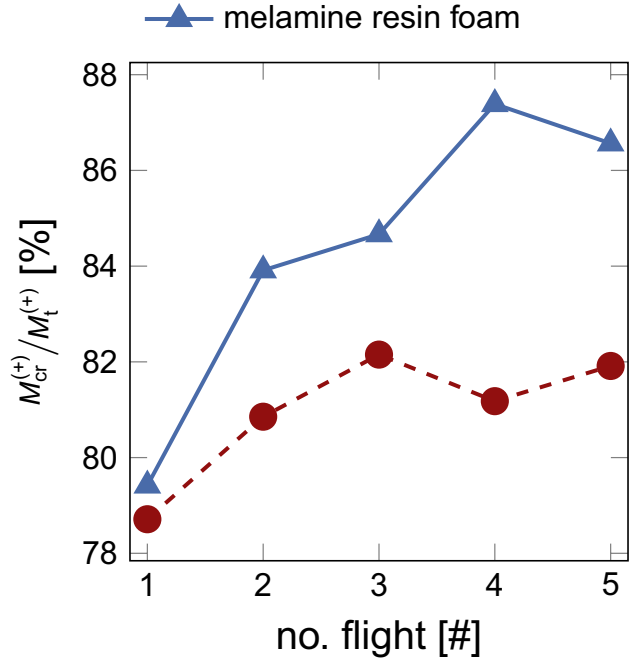

(b) mass ratio cruise with water after the third flight. For the cruise, an opposite behaviour is found for flight 1 . Here, the ratio $M_{\mathrm{cr}}^{(+)} / M_{\mathrm{t}}^{(+)}$is minimal for both insulation materials. Furthermore, for the fibreglass, the ratio $M_{\mathrm{cr}}^{(+)} / M_{\mathrm{t}}^{(+)} \approx 81 \%$ is almost constant for the following flight, while the ratio for the melamine resin foam increases by $4 \%$ from flight 2 to 4 . At the end of flight 4 , the maximum of $M_{\mathrm{cr}}^{(+)} / M_{\mathrm{t}}^{(+)}$is reached. The increase in the ratio during the cruise and the simultaneous decrease during the climb in case of the melamine resin foam reflects that the processes of phase change just take place on the surface and in the insulation blanket facing the air flow. This is in accordance with the results presented above.

Up to now, the mass transfer due to phase transition was discussed. However, in case of forced convection with phase transition, a mutual interplay between the heat transport and mass transfer exists. Apart from this, the water accumulation in the insulation blankets modifies the thermal resistance of the insulation blankets which in turn influences the heat transport between the fuselage and the air flow in the gap.
With the objective to identify the impact of the accumulated water in the insulation blankets on the heat transfer, Fig. 9 illustrates the total heat flux

$\dot{Q}_{\mathrm{t}}=\dot{M}_{\mathrm{air}} c_{\mathrm{p}}^{\mathrm{air}} \Delta T_{\mathrm{t}}$

as a function of time. Here, $\dot{M}_{\text {air }}$ denotes the mass flow of the moist air, $c_{\mathrm{p}}^{\text {air }}$ the specific heat capacity and $\Delta T_{\mathrm{t}}$ the temperature difference between mean temperature at the inlet $\Delta T_{\mathrm{i}}$ and mean temperature at the outlet $\Delta T_{\mathrm{o}}$. The heat flux obtained for the fibreglass is coloured red, while the melamine resin foam is depicted in blue. In principle, both insulation materials reveal a comparable behaviour for the single periods. During the climb, the heat flux increases linearly due to the linear temperature decrease in the cooling plate. During the cruise phase, the heat flux further increases, although the fuselage temperature is constant. Moreover, at the end of the cruise flight, the heat flux is almost constant. This is easy to understand taking into account that the heat
Fig. 9 Total heat flux as a function of time for the fibreglass (red) and melamine resin foam (blue) for a sequence of five flights

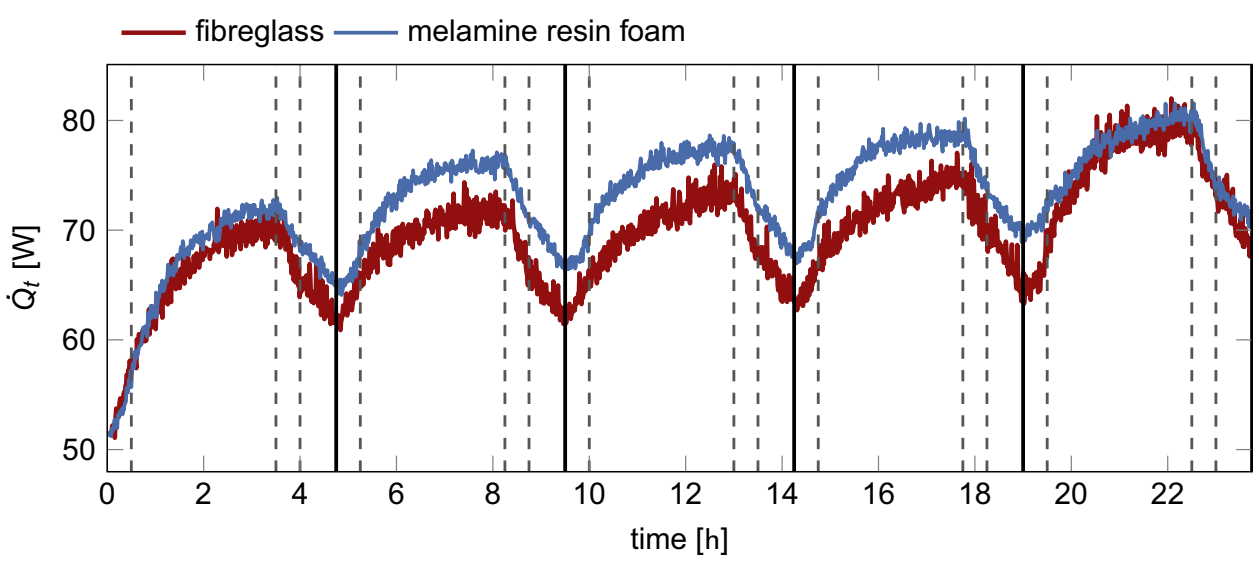


capacity of the insulation blankets is very low. Hence, the cooling of the insulation blanket requires almost the total time of the cruise to reach a state of equilibrium. Finally, in the descent and ground phase, the heat flux decreases due to the increasing temperatures. Furthermore, the overall heat flux increases for the following flights for both insulation blankets. The reason for the higher heat flux is the increasing thermal transmittance between the cooling plate and the region of air flow caused by the water accumulation in the insulation blankets. The time-averaged thermal transmittance

$k=\frac{\dot{Q}_{\mathrm{t}}}{A\left(T_{\mathrm{m}}-T_{\mathrm{f}}\right)}$,

where $\dot{Q}_{\mathrm{t}}$ denotes the total heat flux, $A$ the area of the cooling plate and $\left(T_{\mathrm{m}}-T_{\mathrm{f}}\right)$ the temperature difference between the mixing temperature $T_{\mathrm{m}}$ and the fuselage temperature $T_{\mathrm{f}}$, for the cruise phase as a function of the flight number is illustrated in Fig. 10a. The error bars indicate the standard deviation. For both insulation materials, the heat transmittance increases successively. During the period of condensation, however, two competing effects lead to a change of the thermal transmittance between the bulk and the cooling plate. On one hand, the rime layer on the cooling plate represents an additional heat resistance and leads to a decreasing heat transfer on the cooling plate. On the other hand, the water accumulation in the insulation blanket results in an increasing thermal conductivity. Here, the latter effect dominates and results in a higher heat flux (see Fig. 9).

Furthermore, Fig. 10a reveals a lower heat transmittance coefficient for the fibreglass. This indicates that the insulation effect of the fibreglass is better than the insulation effect of the melamine resin foam. As a consequence, for the present gap flow with the blanket made of melamine resin foam, the heat flux is higher (Fig. 9). However, at the end of flight 5 , the heat flux for the melamine resin foam (Fig. 9) is nearly the same as for the fibreglass. In particular, at the end of flight 5 , the heat fluxes obtained for the two insulation materials are almost equal, and the difference in the heat transmittance is significantly smaller (Fig. 10a) than for flights 2-5. Moreover, the time-averaged heat transmittance coefficient of the fibreglass for the ground phase of flight 5 (Fig. 10b) exceeds that of the melamine resin foam.

\section{Discussion and conclusions}

We performed a study simulating the moisture transfer and heat transport in the gap between fuselage and cabin wall in case of displacement ventilation with active gap flow for the flight scenario Alaska and three different setups: no insulation, insulation blankets made of fibreglass and insulation blankets made of melamine resin foam. The heat transport and the moisture transfer in the gap between fuselage and cabin wall for passenger aircraft are quite complex. With the objective, to obtain valid and comparable results, measurements were performed in a laboratory experiment simulating the conditions of a real flight based on a concept of scaling. The measurements were performed in a gap wind tunnel with a rectangular cross-section with flat, smooth walls. However, the aircraft's shells are rough and curved, although the curve radius is rather small. In addition, the insulation blankets in a realistic aircraft are not mounted perfectly and due to leakages, moist air gets into the layer between insulation blanket and shell. Even though the discussion above reveals differences between the gap in an aircraft and our
Fig. 10 The time-averaged heat transmittance as a function of the flight number for the fibreglass (red) and melamine resin foam (blue) for the cruise (a) and ground phase (b)

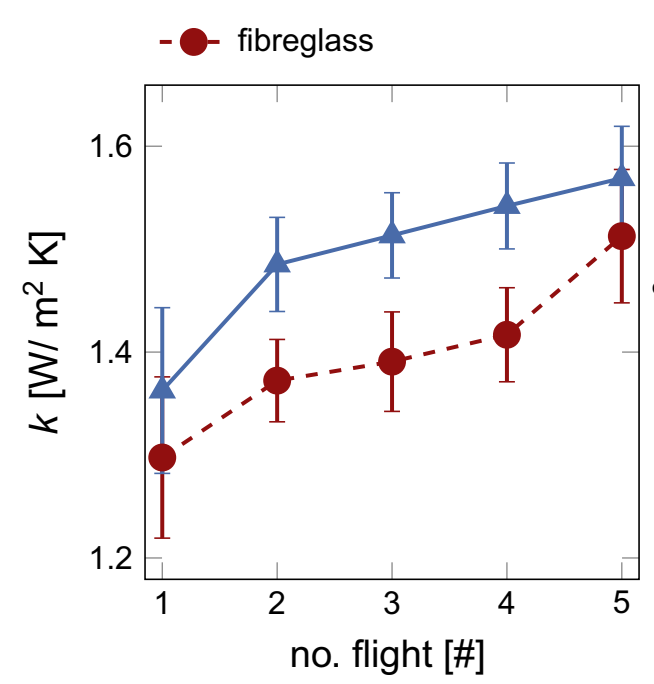

(a) cruise

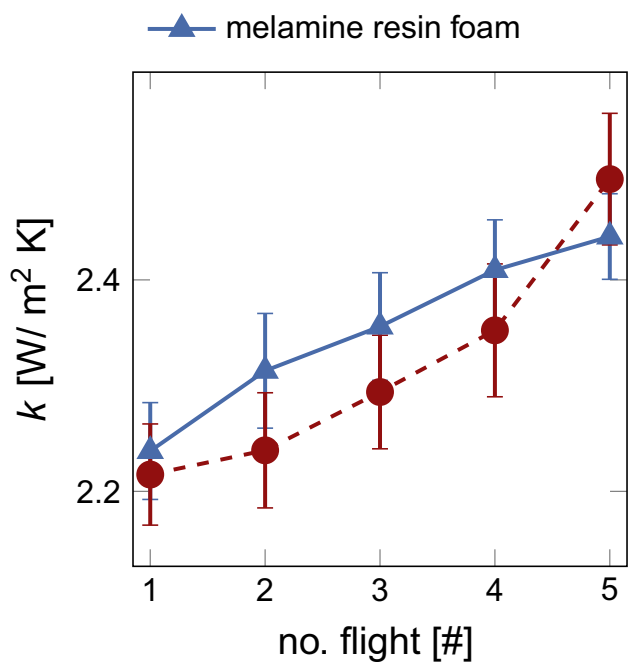

(b) ground 
laboratory setup, the following conclusions can be drawn from the results.

1. For all configurations, with insulation or without insulation, the following was found: during the climb the condensation rate increases and reaches its maximum during this period. Furthermore, during the cruising flight, the condensation rate decreases slowly although the boundary conditions are constant. With the beginning of the descent period, the condensation rate decreases drastically and in the following, the condensation water starts to evaporate. During the ground period, water evaporates.

2. Without insulation blanket, the temperature of the air stream in the gap is not high enough to prevent a permanent agglomeration of frozen water on the cold surface. Here, the mass of the frozen water and thus the height of the rime layer increases continuously during the climb and the cruising flight. The amount of water which evaporates during the end of the descent and ground period is considerably smaller than the mass transfer due to condensation. Consequently, after four flights, the mass of the condensation water in the gap amounts to $1700 \mathrm{~g}$. Hence, a risk of a total obstruction cannot be ruled out, in particular, for flight scenarios in which the temperature on the ground is below the freezing point.

3. With insulation, the mass transfer due to phase transition is up to 40 times smaller compared to the case without insulation. For both types of insulation blankets, the averaged height of the rime layer on the cooled surface is less than $1 \mathrm{~mm}$ at any time during the simulated flights. Hence, we can conclude that with insulation blankets, displacement ventilation and an air return through the gap with a height of $50 \mathrm{~mm}$ between fuselage and cabin wall do not seem critical regarding a total obstruction of the gap. Moreover, no relevant pressure drop leading to a breakdown of the air circulation is expected. Of course, as mentioned above, in a real configuration, the blankets are not mounted in the same way as in to our experiments. In a real aircraft, additional moisture gets between fuselage and primary insulation due to leakage. The increased flow of warm and moist air into the layer between fuselage and primary insulation may result in a higher condensation rate. On one hand, a higher vapour mass transfer could result in an elevated condensation rate and thus a higher rime layer on the fuselage surface. On the other hand, the warmer air, which enters the layer, leads to increased temperatures, which in consequence results in a lower condensation rate. Whether the one or the other effect is predominant depends on a plethora of parameters and the configuration, thus making an exact quantification for the height of the rime layer on the surface impossible.
4. The warm air from the cabin streaming through the gap have an additional positive effect. The results of this study indicate that the air stream in the gap leads to a lower condensation rate. In addition, on the ground the rime layer melts and most of the water evaporates. In the following, a part of the water in the blankets, and the moisture is taken away by the air flow. The effects to be mentioned are reduced shell corrosion, better thermal insulation and lower fuel consumption. Furthermore, in a real aircraft, the gap is additionally equipped with a secondary insulation on the cabin wall. If ones consider now that in our experiments the mean air temperature in the gap between primary insulation and cabin wall (without a secondary insulation) never falls below $20^{\circ} \mathrm{C}$ (for an inflow temperature of $24^{\circ} \mathrm{C}$ ) the question arises whether a second insulation is required at all.

5. The study also reveals differences between the two insulation blankets regarding mass transfer due to phase transition. Starting with the third flight a significantly higher condensation rate for the fibreglass blanket (state of the art) compared to the blanket made of melamine resin foam is found. For the fibreglass, the increase of condensate water, which remains in the blanket at the end of each flight, is constant, while it deceases linearly in case of the melamine resin foam. In total, after five flights the cumulative sum of condensate water in the blankets is twice as high for the fibreglass insulation. Moreover, for the melamine resin foam, nearly, the complete water (83\%), which condensates during the climb and cruising flight, evaporates at the descent and ground stage, while for fibreglass the percentage is just $31 \%$.

6. The corresponding global heat transport for the gap flow is similar for both insulation blankets. With increasing moisture accumulation in the insulation blankets, the insulation effect of the blankets decreases. However, we assume that a significantly lower insulation effect for the fibreglass will be obtained for additional flights due to the successively higher mass of water accumulations.

Acknowledgements Open Access funding provided by Projekt DEAL. This research has been funded by the Federal Ministry of Economics and Technology of Germany in the project interdisciplinary cabin architecture (project number 20K1104D).

Open Access This article is licensed under a Creative Commons Attribution 4.0 International License, which permits use, sharing, adaptation, distribution and reproduction in any medium or format, as long as you give appropriate credit to the original author(s) and the source, provide a link to the Creative Commons licence, and indicate if changes were made. The images or other third party material in this article are included in the article's Creative Commons licence, unless indicated otherwise in a credit line to the material. If material is not included in the article's Creative Commons licence and your intended use is not permitted by statutory regulation or exceeds the permitted use, you will 
need to obtain permission directly from the copyright holder. To view a copy of this licence, visit http://creativecommons.org/licenses/by/4.0/.

\section{References}

1. Sun, Y., Zhang, Y., Wang, A., Topmiller, J.L., Bennet, J.S.: Experimental characterization of airflows in aircraft cabins, part I: Experimental system and measurement procedure. ASHRAE Trans. 111, 2 (2005)

2. Zhang, Y., Sun, Y., Wang, A., Topmiller, J.L., Bennett, J.S.: Experimental characterization of airflows in aircraft cabins, part II: Results and research recommendations. ASHRAE Trans. 111, $2(2005)$

3. Bianco, V., Manca, O., Nardini, S., Roma, M.: Numerical investigation of transient thermal and fluidynamic fields in an executive aircraft cabin. Appl. Therm. Eng. 29(16), 3418-3425 (2009)

4. Bosbach, J., Lange, S., Dehne, T., Lauenroth, G., Hesselbach, F., Allzeit, M.: Alternative ventilation concepts for aircraft cabins. CEAS Aeronaut. J. 4(3), 301-313 (2013)

5. Jacobs, P., De Gids, W.F.: Individual and collective climate control in aircraft cabins. Int. J. Veh. Des. 42(1-2), 57-66 (2006)

6. Wang, A., Zhang, Y., Sun, Y., Wang, X.: Experimental study of ventilation effectiveness and air velocity distribution in an aircraft cabin mockup. Build. Environ. 43(3), 337-343 (2008)

7. Kühn, M., Bosbach, J., Wagner, C.: Experimental parametric study of forced and mixed convection in a passenger aircraft cabin mock-up. Build. Environ. 44(5), 961-970 (2009)

8. Airplanes-Boeing Commercial. The airplane cabin environmentthe air that you breathe. Boeing, Seattle (2005)

9. Specht, P.R., Asfia, J.F., Buzza, T.G., Von Flotow, A.: Air curtain insulating system for aircraft cabin, 1999. US Patent 5,897,079 (1999)

10. Matthias G.: Kondenswasser an Bord. Flug Revue (10) (2003)

11. Qiangmin, B.L.: Displacement ventilation: principles, design and applications. HV \& AC 5, 016 (2000)

12. Bosbach, J., Heider, A., Dehne, T., Markwart, M., Gores, I., Bendfeldt, P.: Evaluation of cabin displacement ventilation under flight conditions. ICAS2012, paper, vol. 304, pp. 23-28 (2012)

13. Müller, D., Schmidt, M., Müller, B.: Application of a displacement ventilation system for air distribution in aircraft cabins. AST $2011(2011)$
14. Zhang, T.T., Tian, L., Lin, C.-H., Wang, S.: Insulation of commercial aircraft with an air stream barrier along fuselage. Build. Environ. 57, 97-109 (2012)

15. Oh, S., Revankar, S.T.: Experimental and theoretical investigation of film condensation with noncondensable gas. Int. J. Heat Mass Transf. 49(15-16), 2523-2534 (2006)

16. Tritton, D.J.: Physical Fluid Dynamics. Springer, Berlin (2012)

17. Roche, P.-E.: Applicability of boussinesq approximation in a turbulent fluid with constant properties. arXiv:0710.3497 (arXiv preprint) (2007)

18. Westhoff, A.: Verbundprojekt Interdisziplinäre Kabinenarchitekturen (INDIKAR): Auslegung eines aktiven Luftsystems für Quelllüftung. Technical Report 10.2314/GBV:870123505, German Aerospace Center (DLR) Institute of Aerodynamics and Flow Technology (2016)

19. Nickl, M., Westhoff, A., Steinmacher, B., Wagner, C.: Experimental Study of Heat and Mass Transfer of Moist Air in Convective, Asymmetric Cooled, Vertical Gap Flows. In: ICHMT Digital Library Online. Begel House Inc., New York (2015)

20. SONNTAG, D.: Important new values of the physical constants of 1986, vapour pressure formulations based on the its-90, and psychrometer formulae. Z. Meteorol. 70(5), 340-344 (1990)

21. Garrels, N., Wenck, H.-D.: Ermittlung der Sorptionsisothermen von Microlite AA42 Glasswolle und Polyimidschaum. Technical note TN EVA-3756/98 EXP-002/98, Daimler-Benz Aerospace Airbus (1998)

22. Tsilingiris, P.T.: Thermophysical and transport properties of humid air at temperature range between $0^{\circ}$ and $100^{\circ} \mathrm{C}$. Energy Convers. Manag. 49(5), 1098-1110 (2008)

23. Bosbach, J.: Auslegung und Verifikation neuer Verfahren der Kabinenbelüftung für Verkehrsflugzeuge. Technical Report 10.2314/GBV:771102100, German Aerospace Center (DLR) Institute of Aerodynamics and Flow Technology (2013)

Publisher's Note Springer Nature remains neutral with regard to jurisdictional claims in published maps and institutional affiliations. 